\title{
ВЛИЯНИЕ МИКРОКЛИМАТА НА РЕЗУЛЬТАТЫ МОДЕЛИРОВАНИЯ ГОРОДСКОГО ОСТРОВА ТЕПЛА (НА ПРИМЕРЕ ГОРОДА АПАТИТЫ)
}

Демин В.И. ${ }^{1}$, Козелов Б.В. ${ }^{1}$, Собакин А.П. ${ }^{2}$, Меньшов Ю.В. ${ }^{3}$, Горбань Ю.А ${ }^{4}$.

${ }^{1}$ Полярный геофизический институт, Апатиты, demin@pgia.ru

${ }^{2}$ Апатитская ТЭЦ филиала «Кольский» ПАО «ТГК-1», Апатиты

${ }^{3}$ Территориально-ситуационный центр ФКУ Упрдор «Кола», Петрозаводск

${ }^{4}$ СЗФ ФГБУ «Авиаметтелеком Росгидромета», Мурманск

\section{Аннотация}

Исследована временная динамика положительной аномалии температуры воздуха в г. Апатиты в зимний период. Время её появления и величина не совпадают с типичными суточными вариациями антропогенного потока тепла. Разность температур между верхней частью городского и фонового холма не увеличивается вместе с ростом теплопотребления в городе, что свидетельствует о небольшой интенсивности городского острова тепла.

\section{Введение}

Хозяйственная деятельность в городе сопровождается существенной модификацией радиационных, термических, влажностных и аэродинамических характеристик ландшафта. Наглядным климатическим следствием таких изменений является появление городского острова тепла (ГОТ). Как правило, под ним подразумевают более высокие температуры воздуха внутри застройки по сравнению с её значением на окружающей сельской местности, хотя в общем виде тепловая аномалия, создаваемая городом, захватывает не только приземный слой атмосферы, но также прослеживается в температуре почвы (поверхности и на глубинах) и грунтовых вод.

Как следует из самого определения ГОТ, для его обнаружения необходимо сравнить температуру воздуха в городе и его ближайших пригородах. В поле температуры ГОТ должен проявляться в виде замкнутых изотерм с горизонтальным градиентом, направленным от окрестностей к центру города или районам с наиболее плотной застройкой. Из-за редкой сети метеорологических станций (MC) провести изотермы вокруг городов довольно сложно и часто ограничиваются сравнением температур воздуха на городской $\mathrm{MC}\left(T_{\text {город }}\right)$ и ближайшей сельской $\mathrm{MC}\left(T_{\text {село }}\right)$. Положительный знак разности:

$$
\Delta T_{\text {ГОТ }}=T_{\text {город }}-T_{\text {село }}
$$

принимают за необходимый признак ГОТ, а её численное значение служит его количественной характеристикой (интенсивность ГОТ).

Однако такой подход не всегда оказывается физически обоснованным. ГОТ по механизмам своего возникновения - явление антропогенное, в то время как разность температур может существовать и за счёт различия естественных микроклиматов. Например, город Апатиты занимает верхнюю часть холма, приподнятого над окружающей местностью на 30-70 м. 
Зимой, а ночью во все сезоны, при установлении тихой и ясной погоды из-за стока холодного воздуха вниз здесь теплее, чем в средних и нижних частях склонов, у подножия холмов и на прилегающей равнине. Так как микроклиматические различия и ГОТ в наибольшей степени проявляются при одинаковых погодных условиях, наблюдаемая в г. Апатиты положительная тепловая аномалия $\left(T_{\text {город }}-T_{\text {село }}\right)$ создается одновременно за счёт стока холодного воздуха и, собственно, ГОТ. Игнорирование рельефа привело к необоснованному завышению интенсивности ГОТ: от $5-8^{\circ} \mathrm{C}$ [12] до $10^{\circ} \mathrm{C}$ [16]. Для сравнения: максимальная интенсивность ГОТ в Лондоне $8.6^{\circ} \mathrm{C}$ [11], Париже $8.0^{\circ} \mathrm{C}$ [13]. Несмотря на уменьшение ГОТ в более поздних работах («средняя интенсивность антропогенного ГОТ составляет 1-1.5 ${ }^{\circ} \mathrm{C}$, а максимальная - примерно $5^{\circ} \mathrm{C}$ 》 [1]) его новое значение по-прежнему является завышенным: МС и датчики в городе в ходе эксперимента оказались расположенными в верхней части холма, а выбранные для контроля фоновые - в средних частях склонов, у подножия холмов, и даже в понижениях рельефа, где минимальные температуры ниже из-за притока к ним холодного воздуха (схема размещения приведена в $[1,17]$ ).

Средняя интенсивность поверхностного ГОТ (температура подстилающей поверхности) в Апатитах по инфракрасным изображениям со спутника, равна $3.2^{\circ} \mathrm{C}$ [5] - на порядок выше характерного значения, рассчитанного по 56 крупнейшим городам Европы в зимний период $\left(0.4 \pm 0.4{ }^{\circ} \mathrm{C}\right.$ [14]). Так как температура подстилающей поверхности, включая и искусственные поверхности, является очень чувствительным к микроклимату термическим параметром, а данная оценка получена без учёта положения города в холмистой местности («Апатиты (Мурманская обл.) ... его равнинное положение... исключает влияние инверсий на температурный режим городской территории» [5]), она также не позволяет говорить о масштабе антропогенного воздействия городского среды на тепловой режим приземного слоя воздуха. Вопрос о реальном значении ГОТ в г. Апатиты остается открытым.

Над территориями с неоднородной подстилающей поверхностью или сложным рельефом прямая оценка ГОТ по данным метеорологических измерений или анализа инфракрасных спутниковых изображений затруднительна из-за присутствия естественных микроклиматических неоднородностей в поле температуры. В г. Апатиты разность температуры между городом и пригородами не выходит за пределы изменчивости температуры, возможной в холмистом рельефе между верхней частью холма и прилегающей равниной [4], что не позволяет надежно выделить ГОТ, который имеет небольшую интенсивность.

Среди методов изучения метеорологического режима городов численное моделирование представляется одним из наиболее перспективных. Представляется интересным вопрос, насколько мезометеорологическое моделирование ГОТ свободно от искажающего влияния микроклимата. 


\section{Использованные данные}

В работе использованы измерения температуры воздуха на автоматических метеорологических станциях (AMC) Полярного геофизического института, Апатитской ТЭЦ, Территориально-ситуационного центра ФКУ «Управление Федеральной автомобильной магистрали Санкт-Петербург Мурманск» (ФКУ Упрдор «Кола»), авиационной метеорологической станции «Апатиты» (АМСГ).

\section{Результаты и обсуждение}

Существует два принципиально различающихся подхода к моделированию метеорологического режима города. Первый - прямое математическое моделирование с помощью решения уравнений газовой динамики и теплообмена. Такие модели требуют очень высокого пространственного разрешения и их использование в масштабах целого города на текущем уровне развития вычислительных технологий технически невозможно.

Второй подход, в котором в последнее десятилетие достигнут значительный прогресс, заключается в параметризации физических процессов. Предполагается, что на территории города каждая модельная ячейка или её часть занята однородной городской средой, которую можно описать набором статистических характеристик (высота зданий, ширина улиц, отношение высоты зданий к ширине улиц, площадь зданий, доля урбанизированной территории в площади модельной ячейки, альбедо и теплофизические свойства искусственных поверхностей).

Помимо искусственных поверхностей, важным фактором, влияющим на городской микроклимат, является выделение значительного количества тепла при сжигании твёрдого и жидкого топлива в бытовых и промышленных целях, в транспортных средствах, а также тепла от работы электрических установок, тепла, возникающее в технологических или метаболических процессах - антропогенный поток тепла (АПТ). Это тепло посредством теплопроводности через стены зданий или напрямую распространяется в приземный слой воздуха, повышая температуру воздуха. Типичные значения АПТ варьируются от 20 до 70 Вт/м² [8], но в крупных городах достигают сотен Вт/м² (что уже сопоставимо с потоком солнечной радиации), а в экстремальных локализованных условиях даже превышают 1000 Вт/м² [10]. Чтобы учесть АПТ в уравнение теплового баланса городской территории добавляется соответствующее слагаемое.

В настоящее время наиболее разработано несколько региональных мезомасштабных моделей атмосферы, широко используемых для оперативного прогноза погоды и научных исследований (например, HIRLAM, COSMO, WRF). В них внедрены специализированные параметризации, необходимые для воспроизведения особенностей городского климата. Эксперименты включают контрольную прогонку со стандартными значениями характе- 
ристик подстилающей поверхности и прогонку в условиях модифицированной городской поверхности и в присутствии АПТ.

В численных экспериментах по воспроизведению временного хода метеовеличин в городе теплофизические характеристики искусственных поверхностей, а также параметры, характеризующие морфологию городской застройки, остаются без изменений даже в условиях активного городского строительства. Анализ многолетних трендов интенсивности ГОТ даёт достаточно оснований для предположения о незначительном влиянии таких изменений в масштабах нескольких лет на климат города.

В то же время АПТ может существенно варьировать даже в течение суток. Согласно существующим теориям, одной из основных причин возникновения ГОТ является эффективное поглощение и сохранение городом солнечной энергии [6]. Однако зимой в арктических городах поступление солнечной радиации незначительно или даже отсутствует (на широте Апатит с 15 по 28 декабря - полярная ночь). В этот период должна наиболее отчётливо проявляться роль АПТ.

Согласно [17] именно АПТ вносит решающую роль в формировании ГОТ в Апатитах. Интенсивность UHI, рассчитанная с помощью мезометеорологической модели COSMO-CLIM со схемой параметризации TERRA URB как разность температур в ячейках модели, включающих городскую территорию и район расположения гидрометеорологической станции (ГМС) «Апатиты» (пос. Тик-Губа, 1.5 км от города), составляет 2-5 ${ }^{\circ} \mathrm{C}$. При расчётах со схемой параметризации TERRA_URB, но без АПТ и без схемы TERRA_URB (модель не была обеспечена информацией об АПТ и модифицированных характеристиках городской подстилающей поверхности), ГОТ не воспроизводился: разность температур между этими же участками составляла $-0.25^{\circ} \mathrm{C}$ и $0.06^{\circ} \mathrm{C}$ соответственно [17].

Точное определение антропогенного потока тепла с достаточным пространственным и временным разрешением является сложной и пока не решённой задачей. Обычно АПТ берется из климатических моделей. Например, в упомянутой схеме TERRA-URB величина AПT определяется для каждого момента времени на основе заданного среднегодового значения с учётом характерного сезонного и суточного и хода (рис. 1). В частности, для
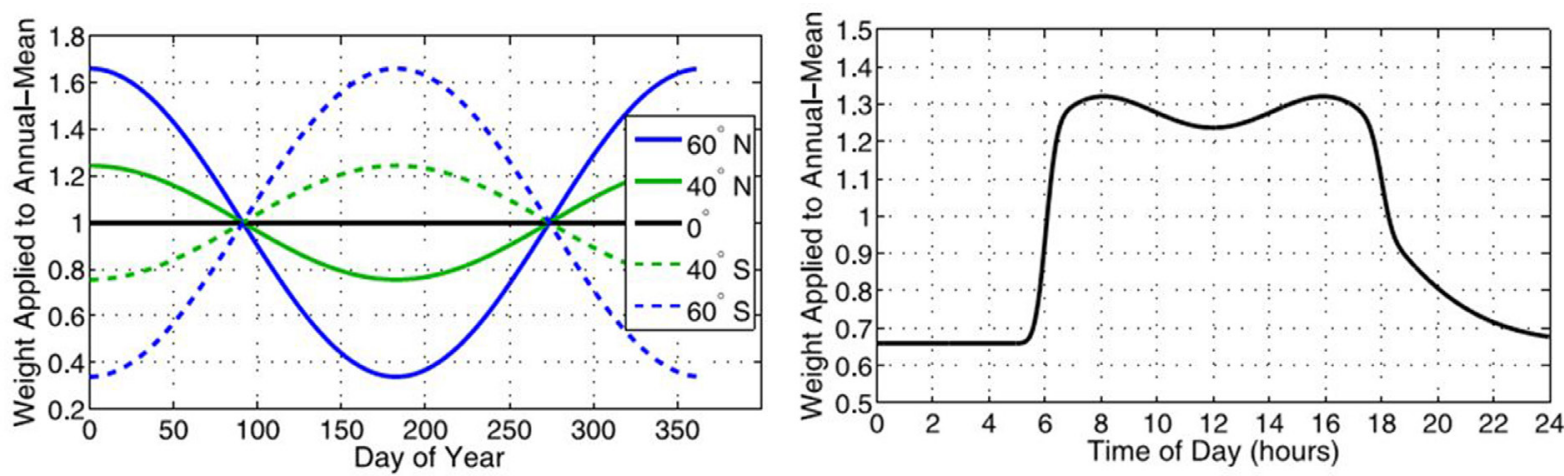

Рис. 1. Коэффициенты для расчёта сезонного (слева) и суточного (справа) хода АПТ [9]. 

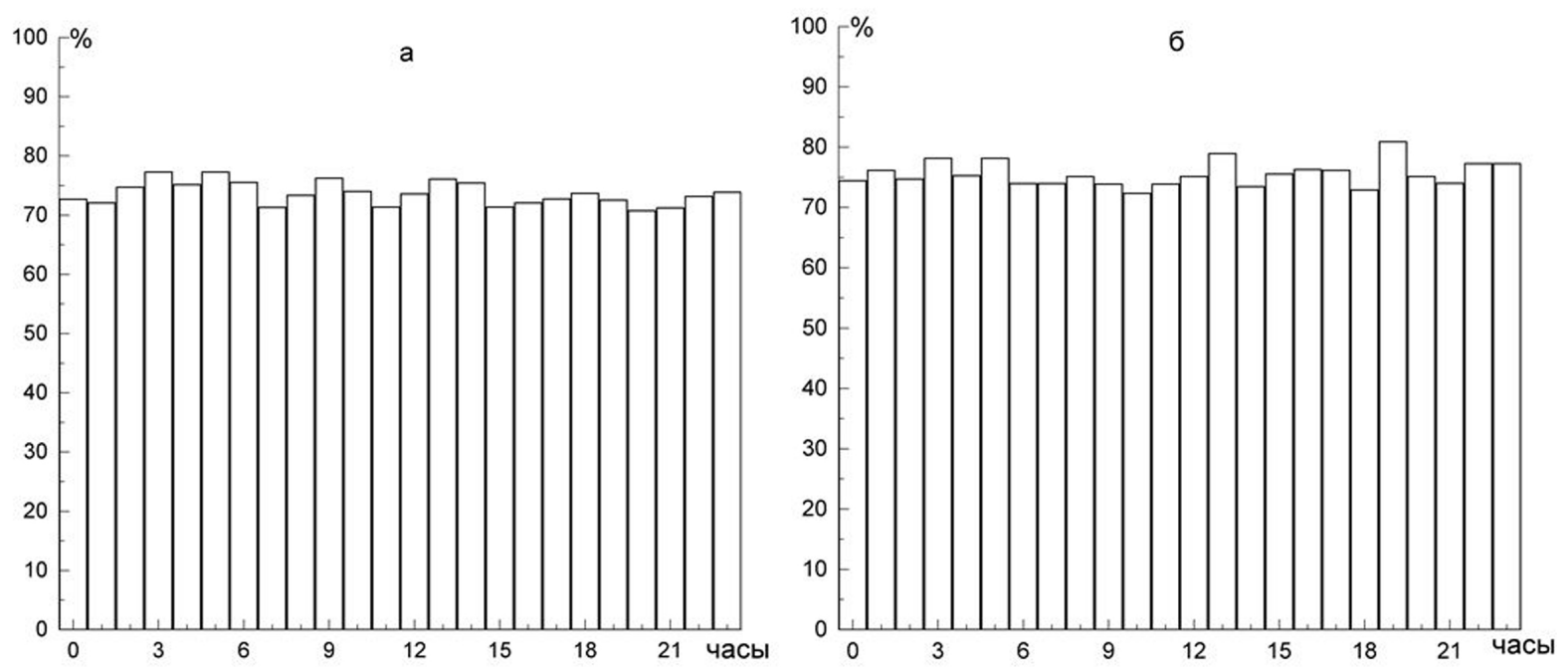

Рис. 2. Вероятность (\%) появления в различные часы положительной аномалии температуры воздуха в г. Апатиты относительно АМСГ «Апатиты»: a - МС «Anатиты, Академгородок» (2014-2018 гг.), б - «Апатиты, Центр» (2016-2018 гг.).

города Апатиты среднегодовое значение АПТ в [17] принималось равным $50 \mathrm{BT} / \mathrm{M}^{2}$, что соответствовало примерно $90 \mathrm{BT} / \mathrm{M}^{2}$ в наиболее холодные зимние месяцы.

АПТ в городе $\left(Q_{F}\right)$ можно представить в идее суммы нескольких компонент:

$$
Q_{F}=Q_{F F}+Q_{F E}+Q_{F H}+Q_{F M},
$$

где $Q_{F F}$ - тепло от сожжённого топлива (предприятия, транспорт, бытовой газ), $Q_{F E}$ - тепло от потребляемой электрической энергии; $Q_{F H}-$ тепло от отопления помещений; $Q_{F M}$ - тепло от метаболических процессов в теле человека (в большинстве работ не рассматривается ввиду его небольшого вклада в суммарную величину АПТ (от 2 до $3 \%$ [15]).

В движении автомобильного транспорта и, как следствие, в объёмах тепла от сгорания топлива, наблюдается очень выраженный суточный ход с пиками в утренние и вечерние часы, небольшим провалом в дневные и сильным минимумом ночью. Суточное потребление электрической энергии также чаще всего имеет два пика - утренний и чуть больший вечерний и два провала - небольшой дневной и глубокий ночной. Даже количество метаболического тепла имеет характерный суточный ход с ночным минимумом, так как зависит от активности человека (например, в [15] принимают для среднего человека 75 Вт ночью (между 23:00 и 05:00) и 175 Вт днём (с 07:00 до 21:00).

Если данные составляющие АПТ вносят заметный вклад в формирование положительной тепловой аномалии в г. Апатиты, время её появления и/или её величина должны иметь суточный ход: положительная аномалия должна чаще появляться в дневные часы и реже ночью и/или быть днём интенсивнее.

На рис. 2 показана вероятность появления в разные часы положительной аномалии температуры в г. Апатиты относительно расположенной в 15 км от 
города фоновой МС (АМСГ «Апатиты»). МС «Апатиты, Академгородок» находится на территории Академгородка (рис. 3), а МС «Апатиты, Центр» - в центральной и наиболее настроенной части города (ул. Бредова, 14) и в большей степени подвержена влиянию ГОТ. На обеих МС время проявления положительной аномалии температуры воздуха не зависит от времени суток, а определяется исключительно погодными условиями (ветер менее $3 \mathrm{M} / \mathrm{c}$, отсутствие сплошной облачности [3]).

Статистика положительных разностей температур между Апатитами («Академгородок», «Центр») и АМСГ «Апатиты» в часы наибольших (6-18 час) и наименьших (22-5 час) значений АПТ (согласно суточному ходу на рис. 1) в виде бокс-диаграмм представлена на рис. 4. Несмотря на различные значения АПТ, средние значения положительных аномалий в дневные и ночные часы на МС «Апатиты, Академгородок» фактически одинаковы 2.0 и $2.1^{\circ} \mathrm{C}$, а на $\mathrm{MC}$ «Апатиты, Центр» 2.0 и $2.0^{\circ} \mathrm{C}$, соответственно.

Статистический анализ показывает, если АПТ и вносит заметный вклад в возникновение положительной аномалии температуры воздуха в г. Апатиты, то, главным образом, за счет тепла, интенсивность выделения которого не зависит от времени суток. Так как на исследуемой территории города Апатиты (рис. 3) нет крупных промышленных предприятий с круглосуточным циклом работы, такой компонентой может быть тепло, затраченное на обогрев зданий.

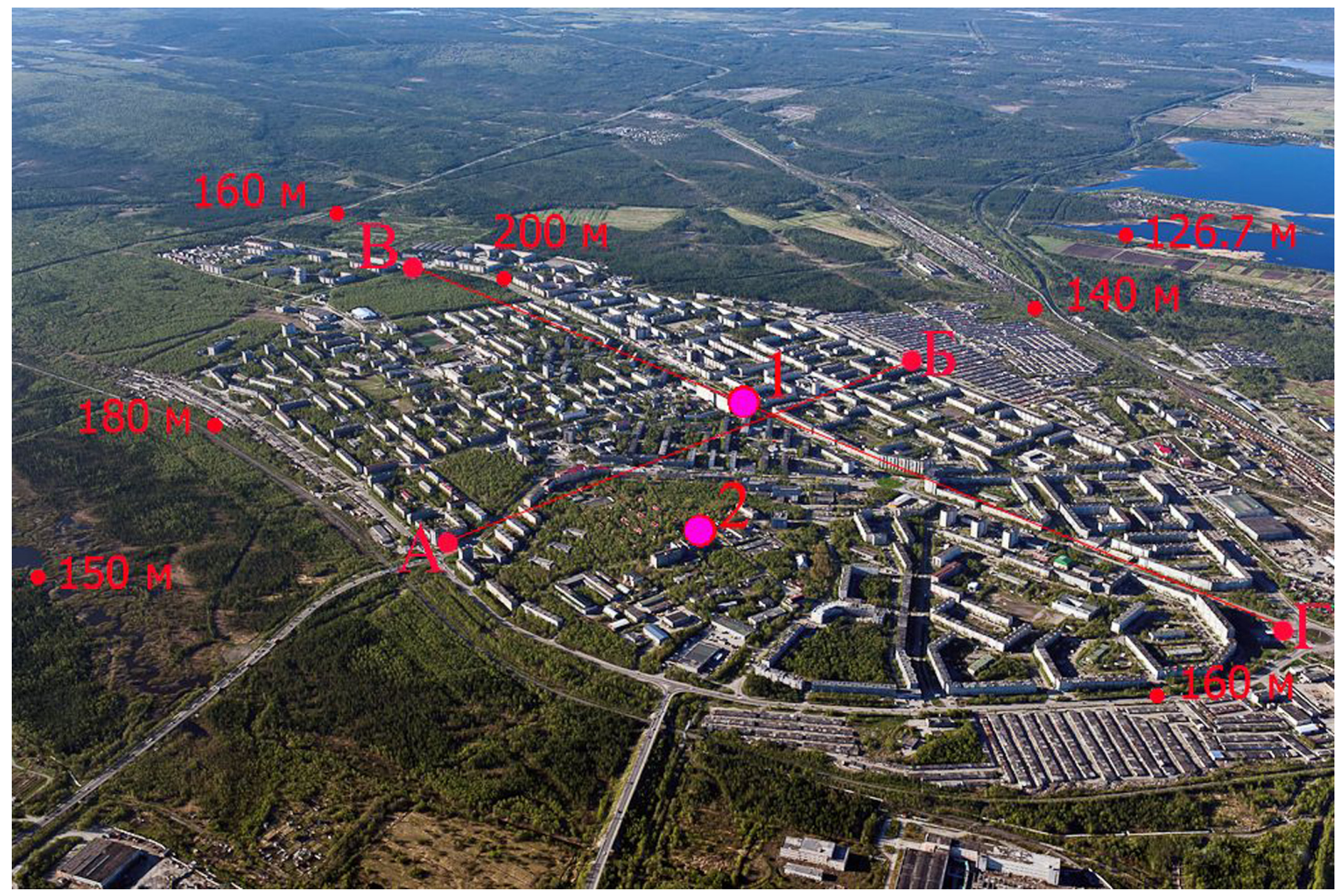

Pис. 3. Anатиты (фото Б. Вахмистрова). Отмечены высоты в м н.у.м.; расстояние $А Б \sim 1.4 \mathrm{kм}$, ВГ $2.8 \mathrm{\kappa м}$; положение городских MC: 1 - MC «Anатиты, Центр», $2-$ МС «Академгородок». 

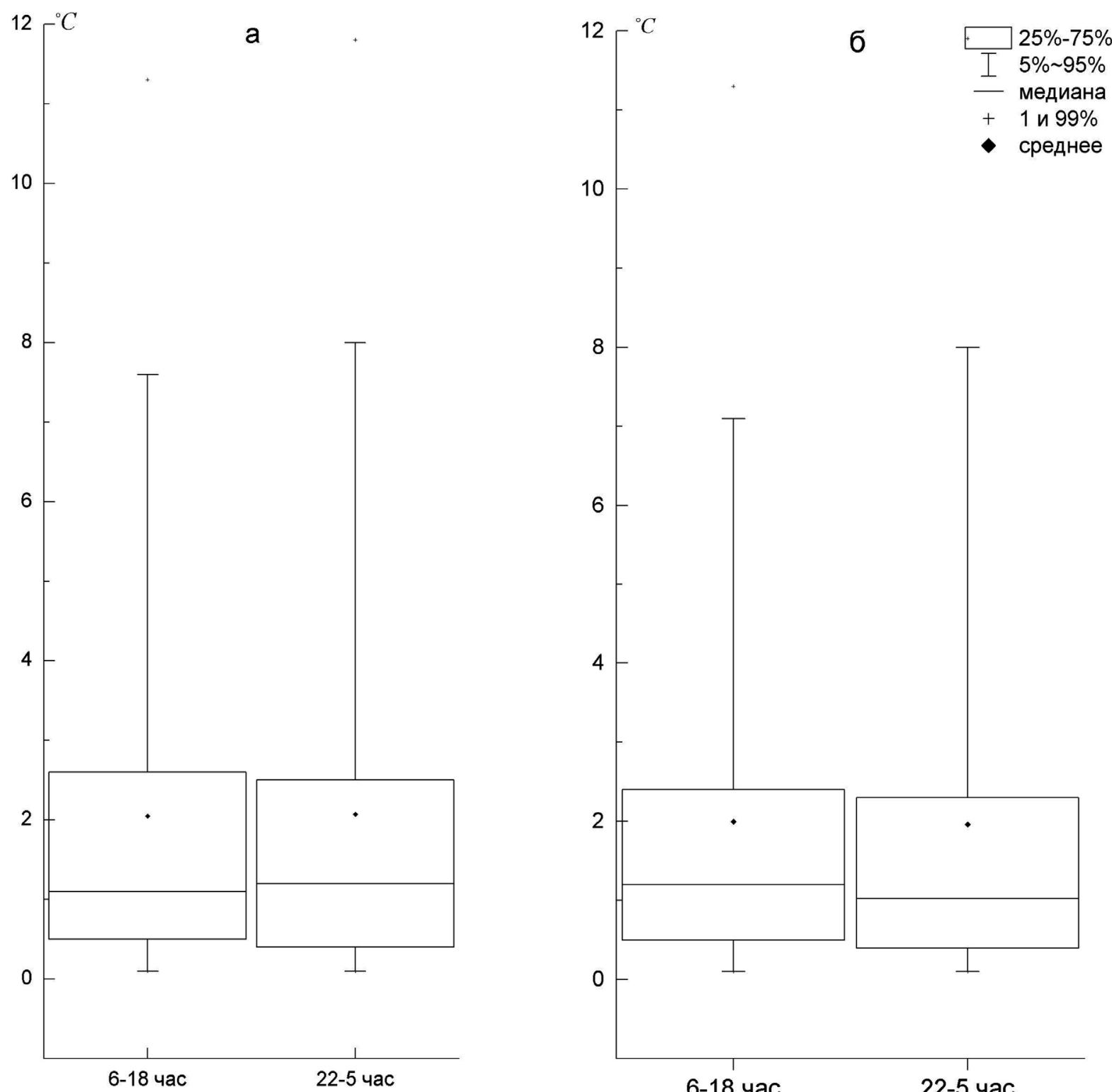

Рис. 4. Положительные аномалии температуры в 2. Апатиты в ночное и дневное время по разности температур на MC «Anатитьл, Академгородок», АМСГ «Аnатиты»» (а), MC «Anатиты, Центр» и АМСГ «Апатит» (б), декабрь-февраль.

Расход тепла в отопительной сети $Q$ пропорционален температуре наружного воздуха $t$ :

$$
Q=Q_{p}^{t} \frac{t_{i}-t}{t_{i}-t_{p}}
$$

где $t_{p}$ - расчётная температура наружного воздуха, $t_{n}$ - температура воздуха в отапливаемых помещениях, $Q_{p}$ - расчётная тепловая нагрузка ТЭЦ соответствующая расчётной температуре $t_{p}$ [7].

На практике отпуск тепла городу не следует за быстрыми изменениями температуры воздуха, а задаётся на ТЭЦ на много часов вперёд. Вследствие тепловой инерции, в работе будут анализироваться не мгновенные значения температуры и отпускаемого ТЭЦ тепла, а среднесуточные значения ГОТ и суточные суммы потребленной городом энергии. 
Были отобраны все дни, когда среднесуточная температура воздуха в г. Апатиты была выше, чем на АМСГ «Апатиты». Как показано на рис. 5, разность среднесуточных температур между городской и фоновой увеличивается вместе с ростом потребляемой городом тепловой энергии. Значительный разброс точек вызван тем, что на разность температур оказывают сильное влияние погодные условия (облачность, скорость ветра и т.д.), которые в течения дня могут меняться. Тем не менее, коэффициент корреляции $(r)$ между данными параметрами статистически значим и равен 0.46. Однако, если на тот же рис. 5 нанести разности температур в те же самые дни между расположенной в верхней части фонового холма автоматической дорожной станцией (АДМС-1166) и АМСГ «Апатиты», которые никак не связаны с теплопотреблением в городе (удалены от города на 15-50 км), мы обнаружим такую же зависимость $(r=0.50)$. Результат объясняется тем, что причиной понижения температуры воздуха часто является радиационное охлаждение подстилающей поверхности и приземного слоя воздуха, возникающее при установлении тихой и малооблачной погоды. Это радиационное выхола-

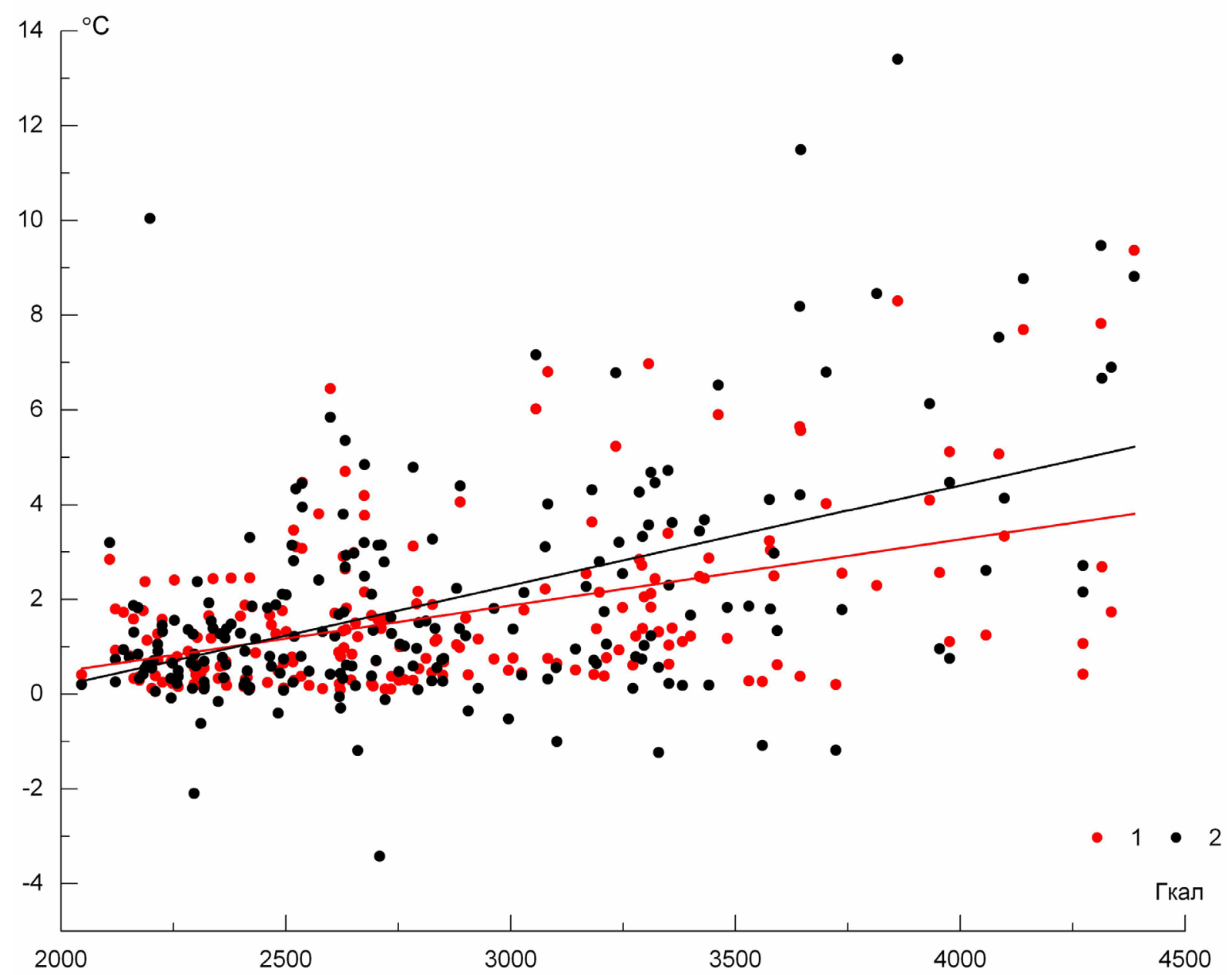

Рис. 5. Зависимость от суточного потребления г. Апатиты тепловой энергии разности среднесуточных температур зимой: г. Anатиты и АМСГ «Anатиты»» (1) и АДМС-1166 и АМСГ «Апатитыл» (2); прим.: выбраны дни с положительной аномалией температуры в городе. 

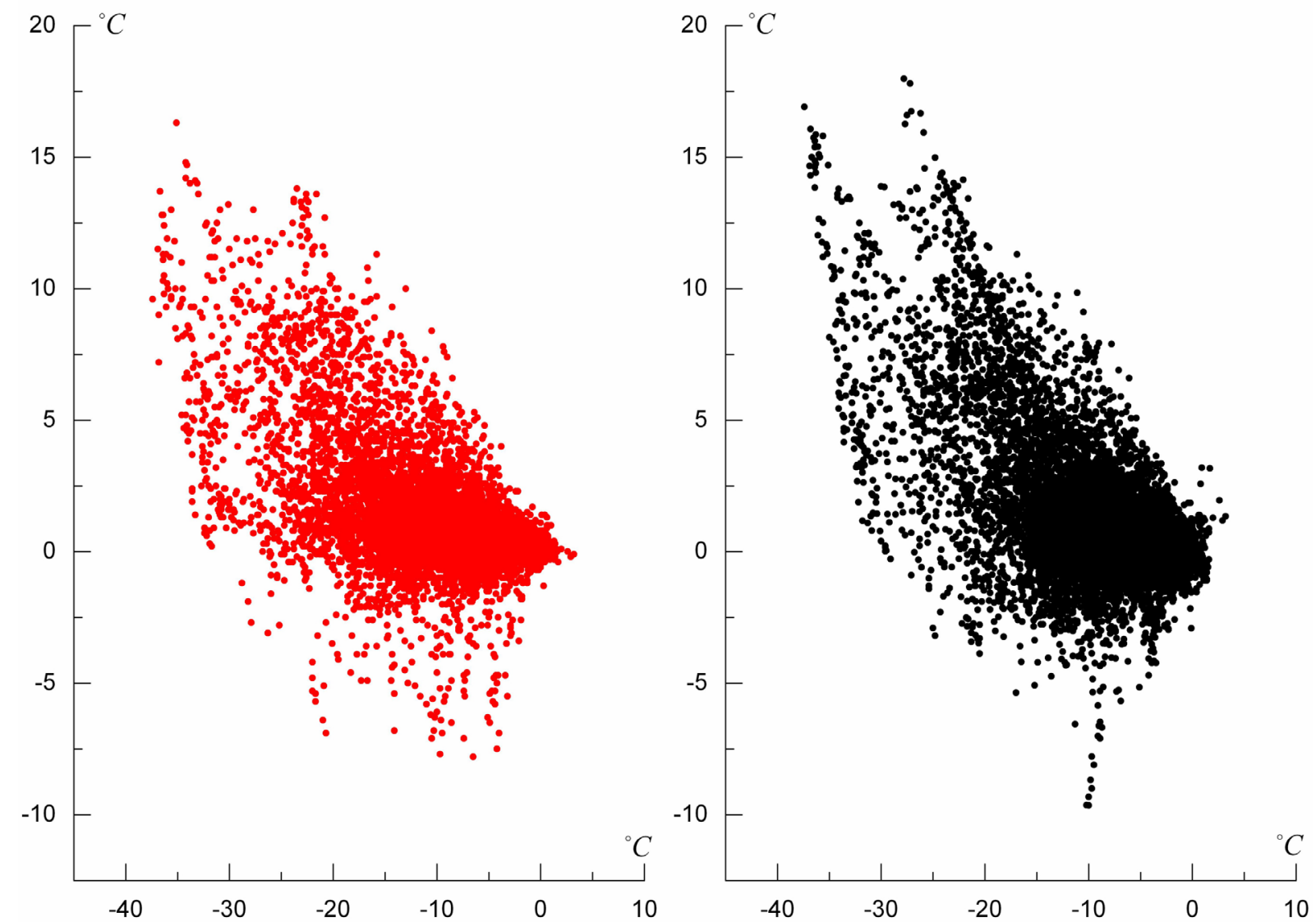

Рис. 6. Разность температуры между верхней частью холма и прилегающей равниной в зависимости от температуры воздуха на равнине: 2. Aпатиты и АМСГ «Anamumbl» (а), АДМС-1166 и АМСГ «Anamumbl» (б), 2014-2018 г2.

живание запускает механизмы, создающие микроклиматические различия по элементам рельефа, приводящие, в частности, к увеличению разности температур между верхней частью холма и прилегающей к нему равниной.

Для иллюстрации на рис. 6 показано, что при общем понижении температуры в регионе увеличение разности температур между верхней частью городского («Апатиты, Академгородок») и фонового холма (АДМС-1166) и прилегающей равниной (АМСГ «Апатиты) происходит примерно одинаково. Аналогичное фоновым условиям понижение температуры воздуха в городе будет сопровождаться усилением потребления тепловой энергии, что приведёт к появлению корреляции между величиной положительной аномалии в городе и количеством потребляемого топлива. Полученный результат говорит о том, что использование мезомасштабных климатических моделей для моделирования ГОТ, в которых одним из входных параметров является АПТ, не гарантирует исключения искажающей роли микроклимата на результаты расчёта.

Различие температур между верхней частью холма, где установлена АДМС-1166, и прилегающей к нему равниной создаётся стоком холодного воздуха. Различие температур между верхней частью городского холма и прилегающей равниной создаётся стоком холодного воздуха и ГОТ. Если ГОТ вносит заметный вклад в величину положительной аномалии темпера- 


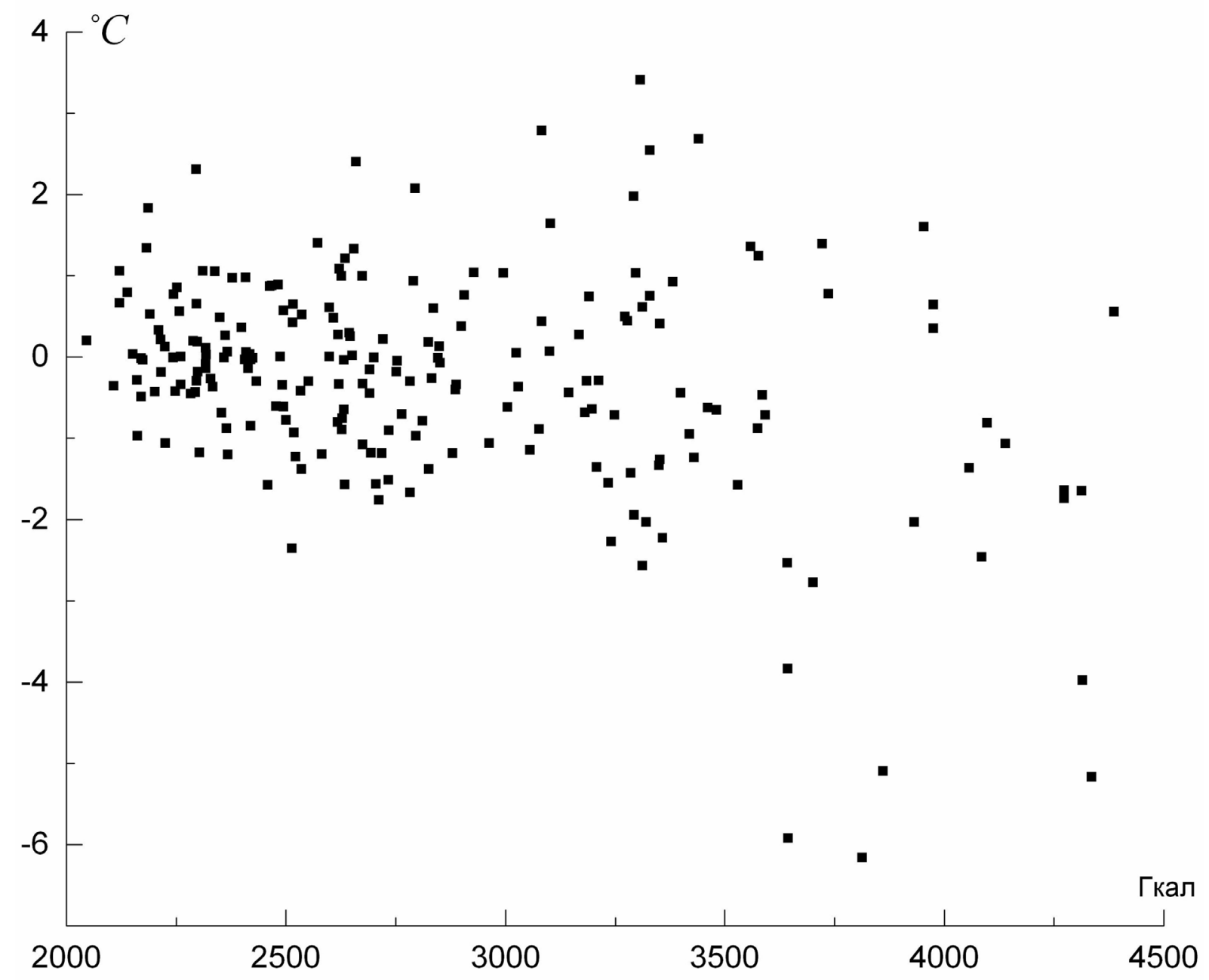

Рис. 7. Зависимость разности среднесуточных температур зимой в г. Aпатить и на АДМС-1166 от суточного потребления тепла г. Апатиты (отобраны дни с положительной температурной аномалией в городе), 2016-2018 г2.

туры воздуха, то разность температуры в городе и на АДМС-1166 должна увеличиваться вместе с ростом теплопотребления. Однако в действительности этого не наблюдается (рис. 7).

Чтобы выделить именно антропогенный эффект, необходимо сравнивать участки со схожим набором естественных процессов, формирующих микроклимат. В случае г. Апатиты зимой, когда снежный покров сглаживает неоднородности подстилающей поверхности, наиболее важным микроклиматическим фактором является положение города в верхней части холма. При оценке ГОТ городские температуры следует сопоставлять с их значениями не на прилегающей к холму равнине, а в верхних частях фоновых холмов.

Такое сравнение уже неоднократно проводилось (см., например, [3, 4]). Для иллюстрации на рис. 8 приведены значения зимних температур в г. Апатиты и на АДМС-1166. АДМС-1166 удалена от Апатит на 50 км к Ю3 (35 км от АМСГ «Апатиты»). Однако обусловленная горизонтальным градиентом разность температур между ними не превышает $0.3^{\circ} \mathrm{C}$, что, очевидно, не помешает выявлению ГОТ, если его величина достигает 5-10 ${ }^{\circ} \mathrm{C}$. Некоторое несовпадение высот между станциями (185 м н.у.м - «Апатиты, Центр», 
200 м н.у.м - «Апатиты, Академгородок» и 210 м н.у.м - АДМС-1166) не играет решающей роли: в холмистом рельефе с относительными превышениями до 100-150 м, эффект высоты перекрывается влиянием неоднородностей подстилающей поверхности и форм рельефа [2]. Стекающий с холма холодный воздух растекается по окружающей равнине; в пределах этого слоя наблюдается значительный вертикальный градиент температуры, а над ним её изменения слабые. Например, в окрестностях г. Апатиты наибольший градиент температуры наблюдается до отметки примерно 170 м н.у.м., а выше в городе (между 170 и 200 м. н.у.м) различия небольшие: средняя разность температур между МС «Апатиты, Центр» и на находящейся в парке на окраине города МС «Апатиты, Академгородок» (200 м н.у.м) зимой всего $0.1^{\circ} \mathrm{C}$.

По результатам измерений 2014-2018 гг. коэффициент корреляции $(r)$ зимних температур в г. Апатиты и на АДМС-1166 равен 0.95. Появление «острова тепла» в г. Апатиты, часто совпадает по времени с появлением такой же теплой области в верхней части холма, на которой находится АДМС-1166. Это объясняется тем, что благоприятная для радиационного выхолаживая и начала стоковых явлений синоптическая ситуация (антициклонические условия с ясным небом и слабым ветром) охватывает сразу большую территорию. Полной синхронности между разностями не наблюдается из-за неоднородностей в поле ветра (по скорости и направлению) и облачности. Нет убедительных оснований говорить о выраженном ГОТ, так
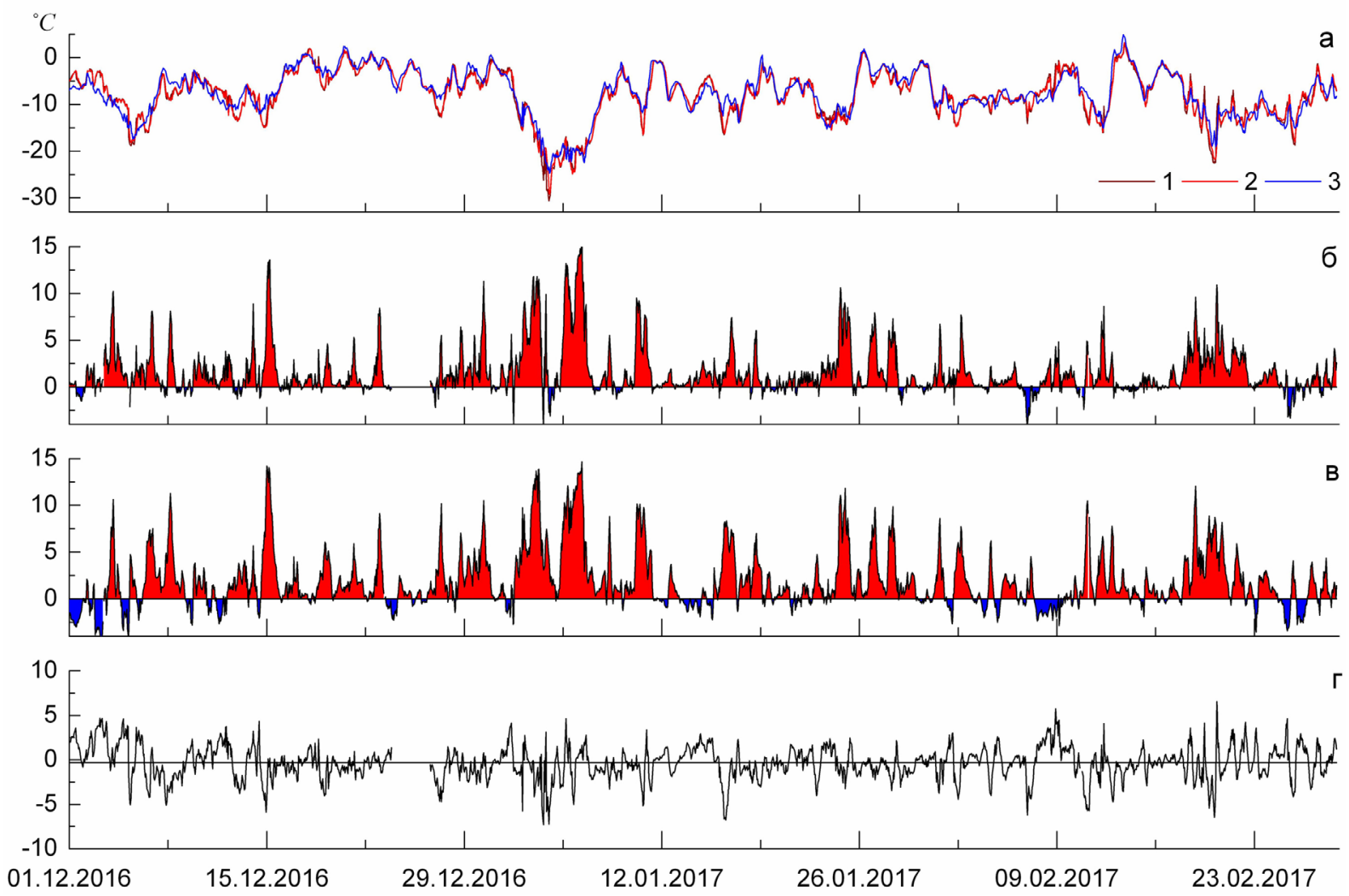

Рис. 8. Температура воздуха (а) в г. Апатиты (1 - «Академгородок», 2 - «Центр») и на АДМС-1166 (3); разность температур между МС «Anатитьл, Академгородок» и АМСГ «Anamumbl» (б), АДМC-1166 и АМСГ «Anamumbl» (в), разности температур на МC «Anатиты, Академгородок» и АДМС-1166 (2). 


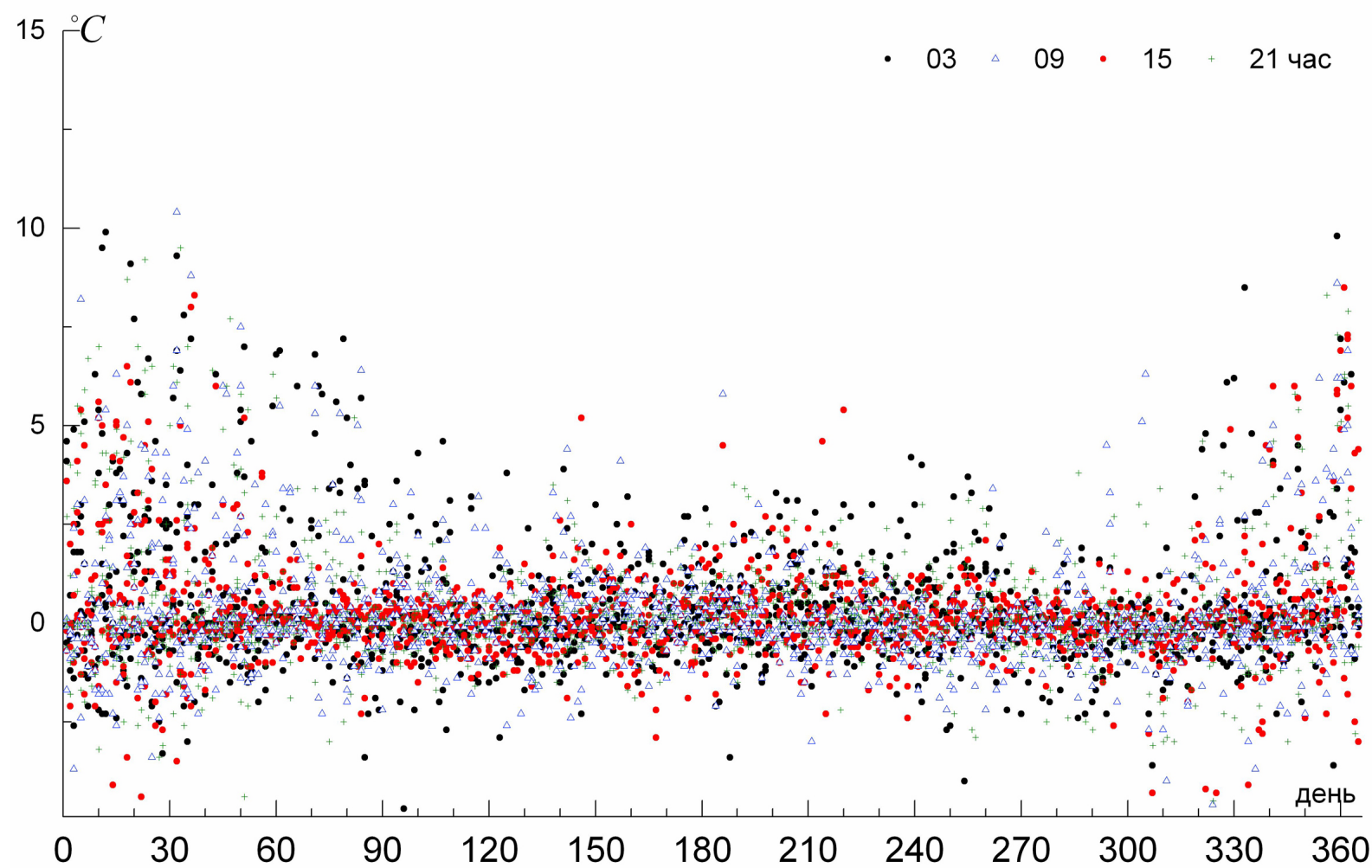

Рис. 9. Разность температур между АМСГ «Апатитыл» и ГМС «Апатитыл», 2014-2018 г2.

как такие же по величине разности, причем часто появляющиеся в то же самое время, возникают между верхней частью фонового холма и прилегающей равниной и без антропогенного воздействия.

Если предполагать заметный антропогенный вклад в возникновении положительной тепловой аномалии, разность температур между г. Апатиты и АДМС-1166 в периоды появления и усиления ГОТ должна увеличиваться. В частности, при антропогенном ГОТ, равном $5^{\circ} \mathrm{C}[1]$, температура воздуха в городе была бы почти на эти $5^{\circ} \mathrm{C}$ выше, чем на АДМС-1166 (точнее - за минусом горизонтального градиента температуры - на $\left.4.7^{\circ} \mathrm{C}\right)$. В действительность разность температур между г. Апатиты и АДМС-1166 не связана с величиной положительной аномалии в г. Апатиты (корреляция отсутствует).

Провёденный анализ показывает, что АПТ никак себя не проявляет в поле температуры воздуха в г. Апатиты, что говорит о очень небольшой интенсивности ГОТ предположительно из-за небольших размеров города воздушная масса быстро пересекает техногенную территорию, не претерпевая существенной трансформации.

Заключение не совпадает с результатами работ [1], согласно которым антропогенный ГОТ в городе составляет в среднем $1-1.5^{\circ} \mathrm{C}$ с максимальным значением до $5^{\circ} \mathrm{C}$. Такая оценка, на наш взгляд, является завышенной, как и в [12, 16], из-за игнорирования микроклимата.

Также заключение не совпадает с результатами моделирования [17], согласно которым примерно 50 \% наблюдаемой разности температур между центром г. Апатиты и ГМС «Апатиты» (Тик-Губа), достигающей $11^{\circ} \mathrm{C}$, объ- 
ясняются антропогенным ГОТ (остальная часть разности создается орографией). На рис. 9 показаны разности температур между фоновыми АМСГ «Апатиты» (160 м н.у.м.) и ГМС «Апатиты» (135 м н.у.м.), находящихся друг от друга на расстоянии около 15 км. Разность температур между этими двумя фоновыми МС зимой достигает 10 и более ${ }^{\circ} \mathrm{C}$ без всякого антропогенного ГОТ и объясняется только особенностями положения ГМС «Апатиты»- орографическая депрессия (на берегу озера Имандра с урезом воды 126.7 м н.у.м.), где накапливается холодный воздух, стекающих с окружающих холмов. Естественная разность температур между верхней частью холма, на котором находится г. Апатиты, и низменными участками (ГМС «Апатиты») может достигать даже больших величин, чем $11^{\circ} \mathrm{C}$ (см., например, рис. 6).

Согласно климатическим данным, в слабохолмистой местности (с относительными превышениями $\leq 50$ м) на Европейской территории России в наиболее холодное время года в верхней части холма по сравнению с ровным местом теплее примерно на $2^{\circ} \mathrm{C}$, а в холмистых районах с относительными превышениями 50-150 м - на 2-3 ${ }^{\circ} \mathrm{C}$. [2]. В этом плане средняя разность между находящейся в городе (в верхней части холма) на высоте 180 м н. и ГМС «Апатиты», равная $1.9^{\circ} \mathrm{C}$ [17], не выходит за пределы естественной микроклиматической изменчивости. В зависимости от погодных условий эта разность меняется в широком диапазоне: от 0 до 4-5 ${ }^{\circ} \mathrm{C}$ в случае возникновения склоновых ветров, а в отдельных случаях и до 8-12 ${ }^{\circ} \mathrm{C}$ [2]. Условия для возникновения больших разностей в Арктике зимой достаточно благоприятные: при круглосуточном отрицательном радиационном балансе и установившейся антициклонической погоде (ясно, штиль) выхолаживание подстилающей поверхности и приземного слоя воздуха может продолжаться в течение многих дней.

\section{Заключение}

Зимой в 70-77 \% времени в г. Апатиты зимой наблюдается положительная аномалия температуры воздуха относительно температуры на окружающей местности. Она создается стоком холодного воздуха вниз (город расположен в верхней части холма, на 30-70 м, возвышающегося над прилегающей равниной) и ГОТ. Время появления положительной аномалии и вариации её величины не согласуются с типичным для городов суточным ходом АПТ. Разность температур между верхней частью городского и фонового холма не увеличивается вместе с ростом теплопотребления в городе, что свидетельствует о небольшой интенсивности ГОТ. Предположительно это может быть вызвано небольшими размерами города (примерно 1.5 на 2.5 км): воздушная масса быстро пересекает техногенную территорию, не претерпевая существенной трансформации.

\section{Список литературы}

1. Варенцов М.И., Константинов П.И. Первичный анализ вклада антропогенного фактора в формирование «острова тепла» города Апатиты по дан- 
ным дистанционного зондирования // Земля из космоса - наиболее эффективные решения. 2018. № 9 (25). С. 27-31.

2. Гольцберг И А. Микроклимат СССР. Л.: Гидрометеоиздат. 1967. 282 с.

3. Демин В.И., Козелов Б.В., Елизарова Н.И., Меньшов Ю.В. Влияние рельефа на формирование «острова тепла» в г. Апатиты // Фундаментальная и прикладная климатология. 2016. № 2. С. 95-106.

4. Демин В.И., Козелов Б.В., Елизарова Н.И., Меньшов Ю.В. Влияние микроклимата на точность оценки городского «острова тепла» // Труды ГГО. 2017. Вып. 584. С. 74-93.

5. Константинов П.И, Грищенко М.Ю., Варенцов М.И. Картографирование островов тепла городов Заполярья по совмещенным данным полевых измерений и космических снимков на примере г. Апатиты (Мурманская область) // Исследование Земли из космоса. 2015. № 3. С. 27-33.

6. Оке Т.Р. Климаты пограничного слоя. Л.: Гидрометеоиздат. 1982. 360 с.

7. Хандожко Л.А. Экономическая метеорология. СПб.: Гидрометиздат, 2005. 491c.

8. Crutzen PJ. New Directions: The growing urban heat and pollution «island» effect - impact on chemistry and climate. Atmospheric Environment. 2004. V. 38. P. 3539-3540.

9. Flanner M.G. Integrating anthropogenic heat flux with global climate models // Geophys. Res. Lett. 2009. V. 36. № 2. P. L02801.

10. Ichinose T, Shimodozono K, Hanaki K. 1999. Impact of anthropogenic heat on urban climate in Tokyo. Atmospheric Environment. V. 33 (24). P. 3897-3909. 11. Kolokotroni M, I. Giannitsaris and R. Watkins. The effect of the London Urban Heat Island on building summer cooling demand and night ventilation strategies. Solar Energy. 2006. V. 80 (4). P. 383-392.

12. Konstantinov P.I. et al. Urban Heat Island's intensity research of Arctic city during winter (Apatity case-study) and its influence on inhabitants' thermal comfort // EMS Annual Meeting Abstracts V. 13. EMS2016-25. 2016.

[https://meetingorganizer.copernicus.org/EMS2016/EMS2016-25.pdf]

13. Lemonsu A. and V. Masson. Simulation of a summer urban breeze over Paris. Boundary-Layer Meteorology. 2002. V. 104. P. 463-490.

14. Peng S.S, Piao S.L., Ciais P. et al. Surface urban heat island across 419 global big cities // Environ. Sci. \& Technol. V. 46. 2011. № 2. P. 696-703.

15. Sailor DJ, Lu L. A top-down methodology for developing diurnal and seasonal anthropogenic heating profiles for urban areas. Atmospheric Environment. 2004. V. 38. P. 2737-2748.

16. Varentsov M. et al. Experimental research of urban heat island effect for the biggest Arctic cities. Arctic Frontiers conference, Tromsø, Norway, January 28, 2016. [https:// istina.msu.ru/download/22094094/1fD7PQ:qWmTumG2ojM7-TmafPxUDs-ZaZA].

17. Varentsov V., Konstantinov P., Baklanov A. et al. Anthropogenic and natural drivers of a strong winter urban heat island in a typical Arctic city // Atmos. Chem. Phys. Discuss. https://doi.org/10.5194/acp-2018-569. 